\title{
Organic constituents in the different stages of regenerated callus of sugarcane Var Co-740
}

\author{
Patil C.S. ${ }^{1}$, Gangawane A.K. ${ }^{2}$, Anjali R. ${ }^{2}$, and Naik G.R. ${ }^{3}$ \\ ${ }^{1}$ Department of Biotechnology, B.V. Bhoomareddy College, Bidar-585 403, Karnataka, India \\ ${ }^{2}$ Department of Biotechnology and Bioinformatics, Dr. D.Y. Patil University, Plot no 50, Sector \\ 15, CBD, Belapur, Navi Mumbai-400614 \\ ${ }^{3}$ Department of Biotechnology, Gulbarga University, Gulbarga-585 106, Karnataka, India
}

\begin{abstract}
In all living organisms there is an increasing procession of chemical reactions and processes, which leads to fundamental internal changes. Living substance is constantly being torn down and built up. The general activities of protoplasm are being maintained. Waste products are being eliminated and vast amount of energy in constantly being expended. The sum total of these processes and changes is called metabolism. The present investigation was under taken to study the changes in organic metabolites of different regenerated stages in sugarcane var. co 740. The organic matters like chlorophyll, protein, proline, and polyphenols, reducing sugar, total sugar starch, moisture percentage and TAN were analyzed.

Keywords- Sugarcane, metabolites, organogenesis, proline
\end{abstract}

\section{Introduction}

Sugarcane is one of the cash crops of India as $60 \%$ of the world sugar. Sugarcane industries is the second largest agro based industry [7]. Sugarcane (saccharum species hybrid) tissue is widely used in sugarcane improvement and breeding programs [2, 5, and 8]. Callus can be initiated from any sugarcane tissue [6].organogenesis is the development of adventitious organs are primordial from undifferentiated cell mass in tissue culture by the process of differentiation $[10,12]$. It has found that addition of auxins to the culture medium to stimulate root formation .Skoog and Miller have reported that organogenesis is controlled by a balance between cytokinin and auxin.Organogenesis studies in vitro conditions helps in understanding the developmental biology of sugarcane tissue culture at metabolic and biochemical level.

\section{Materials and methods}

Three different stages of tissue culture plant material were used for the investigation.

\section{Estimation of Chlorophylls}

Total chlorophylls were estimated by the method of Arnon [1] in which $1 \mathrm{gm}$ of fresh plant material of three different stages was crushed in cold mortar using pestle in $80 \%(\mathrm{v} / \mathrm{v})$ acetone mixed with $2 \mathrm{ml}$ of ammonia (25\%) per liter. During extraction, a pinch of acid washed sand $0.10 \mathrm{gm}$ of MgCo3 was added. Extraction was carried in the dark and cold condition. The extract was filtered through Buchner funnel and used for spectrophotpometric determination of absorbance at 663 and $645 \mathrm{~nm}$. Total chlorophylls were calculated by standard formula.

Chlorophylls $\mathrm{a}+\mathrm{b}=8.02 \times$ Absorption at $663+20.2 \times$ Absorption at $645[Z]$

Total chlorophylls $=$ Z X VOLUME OF EXTRACT X 100

WEIGHT OF PLANT MATERIAL X 100

\section{Estimation of Polyphenols}

Polyphenols are estimated from the various parts using the oven dried powdered material by Folin Denis method [1, 4]. Polyphenols from dried plant material were extracted in $80 \%$ acetone$30 \mathrm{ml}$.the extract was filtered through Whatman no.1 filter paper using Buchner funnel under suction. Polyphenols were extracted repeatedly from the residue. The volume of the filtrate was made to $50 \mathrm{ml}$. The same filtrate was used for estimation of polyphenols. $2 \mathrm{ml}$ of filtrate was taken in $50 \mathrm{ml}$ marked Nesselers tube. in other such tubes different concentration $(0.5,1.0,2.0$ and 4.0 $\mathrm{ml}$ ) of standard polyphenol solution (tannic acids $0.1 \mathrm{mg} / \mathrm{ml}$ ) were taken $10 \mathrm{ml}$ of $2 \% \mathrm{Na} 2 \mathrm{CO} 3$ were then added to each test tube to make the medium alkaline and $2 \mathrm{ml}$ of Folin Denis reagent. 
A blank was prepared without polyphenols solution. The ingredients were allowed to mix thoroughly and after 10 min the optical density of each mixture was read at $660 \mathrm{~nm}$ on spectrophotometer.

\section{Estimation of Proline}

The estimation was carried out by the method of Bates [11]. About $0.5 \mathrm{~g}$ oven dried plant material was homogenized in $10 \mathrm{ml}$ sulphosalicylic acid (3\%) and the extract was filtered through whatman no. 1 filter paper. The assay known quantity of filtrate was mixed with $2 \mathrm{ml}$ of acid ninhydrin reagent. The contents were boiled for 1 hour on boiling water bath and cooled rapidly in freeze ice bath. $4 \mathrm{ml}$ pf toluene was added to each test tube and vigorously shaken for few seconds. The absorbent of toluene chromophere was recorded at 520nm against toluene as blank. Standard curve of proline was prepared for different concentrations for proline estimation.

\section{Estimation of Nitrogen and Protein}

The total nitrogen was estimated by the method of Hawk [1, 3]. About $1 \mathrm{gm}$ of oven dried plant material was taken in kjeldha's flask and $10 \mathrm{ml}$ of $1: 1 \mathrm{H}_{2} \mathrm{SO}_{4}$ and pinch of micro salt $\left(\mathrm{CuSO}_{4}+\mathrm{K}_{2} \mathrm{~S}_{4}\right)$ 1:5 was added. The flasks were kept overnight. Next day the material was digested on hot plate until the fumes subside and a colorless acid digested extract was obtained. The extract was used for estimation of nitrogen colorimetrically at $415 \mathrm{~nm}$ using Nessler's reagent. Total protein was estimated by Bradford method (1976). About $1 \mathrm{gm}$ of fresh sample was homogenized in $0.1 \mathrm{~N}$ $\mathrm{NaOH}$ and centrifuged at $2000 \mathrm{rpm}$, for 15 mins. The supernatant was used for determination of total protein. The absorbance read at $595 \mathrm{~nm}$ with bovine serum albumin was used as standard.

\section{Estimation of Total Soluble Sugars}

The total sugar was estimated by Anthrone method [1, 4]. About $1 \mathrm{gm}$ of material was homogenized in $80 \%$ alcohol. The homogenate was centrifuged at $2000 \mathrm{rpm}$ for $15 \mathrm{mins}$. The alcohol was evaporated on a hot water bath and filtrate was used. The final volume was adjusted to $10 \mathrm{ml}$ by adding distilled water and the extract was used for analysis.

\section{Estimation of Sugars}

Reducing sugars were estimated by Somogyis method [1, 9]. The alcohol evaporated extract was used for analysis.

\section{Estimation of Titrable Acid Number (TAN)}

Titrable acid number was determined by modified method of Thomas and Beevers [6]. About $1 \mathrm{~g}$ of callus from different stages were boiled in $100 \mathrm{ml}$ of distilled water for $1 \mathrm{hr}$. and the filtered through muslin cloth. The filtrate was used for titration. To $10 \mathrm{ml}$ of extract $25 \mathrm{ml}$ of distilled water and 2-3 drops of phenolphthalein indicator was added in an evaporating dish. This was titrated against $\mathrm{N} / 40 \mathrm{NaOH}$. The TAN is expressed as the $\mathrm{ml}$ of decinormal alkali required to neutralize the acids present in $100 \mathrm{~g}$ of material.

\section{Results \\ Chlorophyll Contents}

The results of total chlorophyll contents in different stages of regenerating callus are presented in Table 1 and Figure 2. The callus at the initial stage showed only $10.3 \mathrm{mg}$ of chlorophyll. As regeneration advances due to formation shoot buds the chlorophylls contents has shown linear increase. In the medium green stage, the amount has doubled within the 3-4 weeks of advancement of organogenesis process. This is about $267 \%$ more as compared to medium regenerated stage (IM). Thus our results show that chlorophyll synthesis is rapid in the later stages of regeneration response than at the initial stage.

\section{Polyphenols}

The Table-2 and Figure-4 shows the contents of polyphenols in three stages of callus cells. The polyphenols contents shoe gradual decrease as the cells become green and then develop into shoots. The callus had $912 \mathrm{mg}$ of polyphenols which declined to 460 and $210 \mathrm{mg} / 100 \mathrm{~g}$ as they turn medium green and into green shoot buds respectively. 


\section{Proline}

The quantity of proline contents is shown in the same Table -2 and Figure- 3 . It is one of the important amino acid during growth and development during stress conditions. The proline contents are reduced in the medium green cells while it increases cells in the completely regenerating green seedlings.

\section{Sugars}

Sugars are important constituents of the growing cells. Reducing sugar level in the medium green cells is higher by $55 \%$ than in the non regenerated callus while it is reduced by $37 \%$ in the completely green callus. Similar trend is observed with respect to total sugar and starch contents. It seems that the sugar accumulates in the initially regenerating phase and it is rapidly utilized in the later process of organogenesis. This effect is more pronounced in starch contents of the cell as compared to total soluble sugars as shown in Table-3 and Figure -5 .

\section{Nitrogen and Protein}

Organic constituents from three different stages of regenerating callus of sugarcane were analyzed. The results are shown in Table-2 and Figure 3 and 4. The total nitrogen content showed linear increased by $63.5 \%$ in medium green than in the non-regenerating callus by $29 \%$ in the complete regenerating seedlings. Similar trend is also seen in protein contents as shown in figure-4. As the cells undergo organogenesis, more nitrogen contents are assimilated and used for protein synthesis.

\section{Total Acidification Number}

TAN is defined as a number of decinormal alkali required to neutralize acids present in $100 \mathrm{~g}$ of fresh tissue. It is can be seen in Table 1 and Figure 2 . The acidity values are similar in callus and regenerated shoots. However, TAN has shown a higher level (16\%) in the medium green callus. These results again indicate that the metabolic status of medium green tissue is more active as compared to the non-regenerated cell and regenerated green shoots. The medium green cells along with acquiring high water content are also maintained higher acidity. It seems that the cells from this stage are active in generating more ATP through Krebs cycle and hence show elevated acid level.

\section{References:-}

[1] Balnaco M., Nieves N., Castillo R. and Sanche; (1995) M. Ad. Modern Biotechnology, 3, 11-33.

[2] Barba R. and Nickel N.G; (1969) Planta 89, 299-302.

[3] Ericson M.C. and Alfinto; (1989) PlantPhysio, 74-3, 247.

[4] Folin O. and Davis W; (1915) J. Biol.Chem 22, 305-308.

[5] Henz D.J. and Mea G.W.P; (1969) Crop. Sci, 9,346-348.

[6] Liu M.C. J; (1993) Plant Physio, 141,6, 714-720.

[7] Naik G.R. and Chikgouda N.R; (1997) Indian sugar, 125-130.

[8] Naik G.R. and Joshi G.V; (1983) Proc. Of Indian Acad Sci 92-3,265-269.

[9] Nelson N; (1944) J.Biolo.Chem, 153,375-380.

[10] Plopper and Maelotti T.A; (1977) Throp(Ed), Academic press, 299-323.

[11] Singh N.B and Singh R.G; (1986) J.Plant Physiol, 29, 2, 171-174.

[12] Skoog F; (1944) Am. J. Bot, 31, 19-24. 
Table 1- Moisture, TAN, Chlorophyll contents in the different stages of regenerated shoots of sugarcane variety Co 740

\begin{tabular}{|l|l|l|r|}
\hline Stages & $\begin{array}{l}\text { Moisture } \\
(\%)\end{array}$ & $\begin{array}{l}\text { Total } \\
\text { chlorophyll } \\
(\mathrm{mg} / 100 \mathrm{~g})\end{array}$ & TAN \\
\hline IC & $92.0( \pm 6.8)$ & $10.3( \pm 2.8)$ & $70.6( \pm 8.7)$ \\
\hline IM & $93.6( \pm 5.2)$ & $24.4( \pm 5.4)$ & $82.3( \pm 6.5)$ \\
\hline IR & $95.0( \pm 5.6)$ & $89.6( \pm 10.6)$ & $72.4( \pm 3.5)$ \\
\hline
\end{tabular}

Table 2-Organic constituents in the different stages of regenerated shoots in sugarcane variety Co 740

\begin{tabular}{|l|l|l|l|l|}
\hline Stages & NITROGEN & PROTEIN & POLYPHENOLS & PROLINE \\
\hline & $((\mathrm{mg} / 100 \mathrm{mg})$ & $(\mathrm{mg} / 100 \mathrm{mg})$ & $(\mathrm{mg} / 100 \mathrm{mg})$ & $(\mathrm{mg} / 100 \mathrm{mg})$ \\
\hline & & & & \\
\hline $\mathrm{IC}$ & $0.52( \pm 0.12)$ & $303.2( \pm 2.7)$ & $912( \pm 68.2)$ & $6.6( \pm 1.2)$ \\
\hline & & & & \\
\hline $\mathrm{IM}$ & $0.85( \pm 0.17)$ & $492.0( \pm 28.3)$ & $460( \pm 72.5)$ & $5.2( \pm 1.7)$ \\
\hline & & & & \\
\hline $\mathrm{IR}$ & $1.10( \pm 0.28)$ & $644.8( \pm 25.2)$ & $210( \pm 27.3)$ & $8.2( \pm 0.75)$ \\
\hline
\end{tabular}

Table 3- Carbohydrates in the different stages of regenerated shoots of sugarcane variety Co 740

\begin{tabular}{|l|l|l|l|}
\hline STAGES & $\begin{array}{l}\text { REDUCING } \\
\text { SUGAR }\end{array}$ & $\begin{array}{l}\text { TOTAL } \\
\text { SUGAR }\end{array}$ & STARCH \\
\hline & $(\mathrm{mg} / 100 \mathrm{~g})$ & $(\mathrm{mg} / 100 \mathrm{~g})$ & $(\mathrm{mg} / 100 \mathrm{~g})$ \\
\hline $\mathrm{IC}$ & 5.52 & 6.04 & 7.76 \\
\hline $\mathrm{IM}$ & 8.55 & 12.83 & 2.8 \\
\hline $\mathrm{IR}$ & 5.45 & 8.68 & 3.4 \\
\hline
\end{tabular}




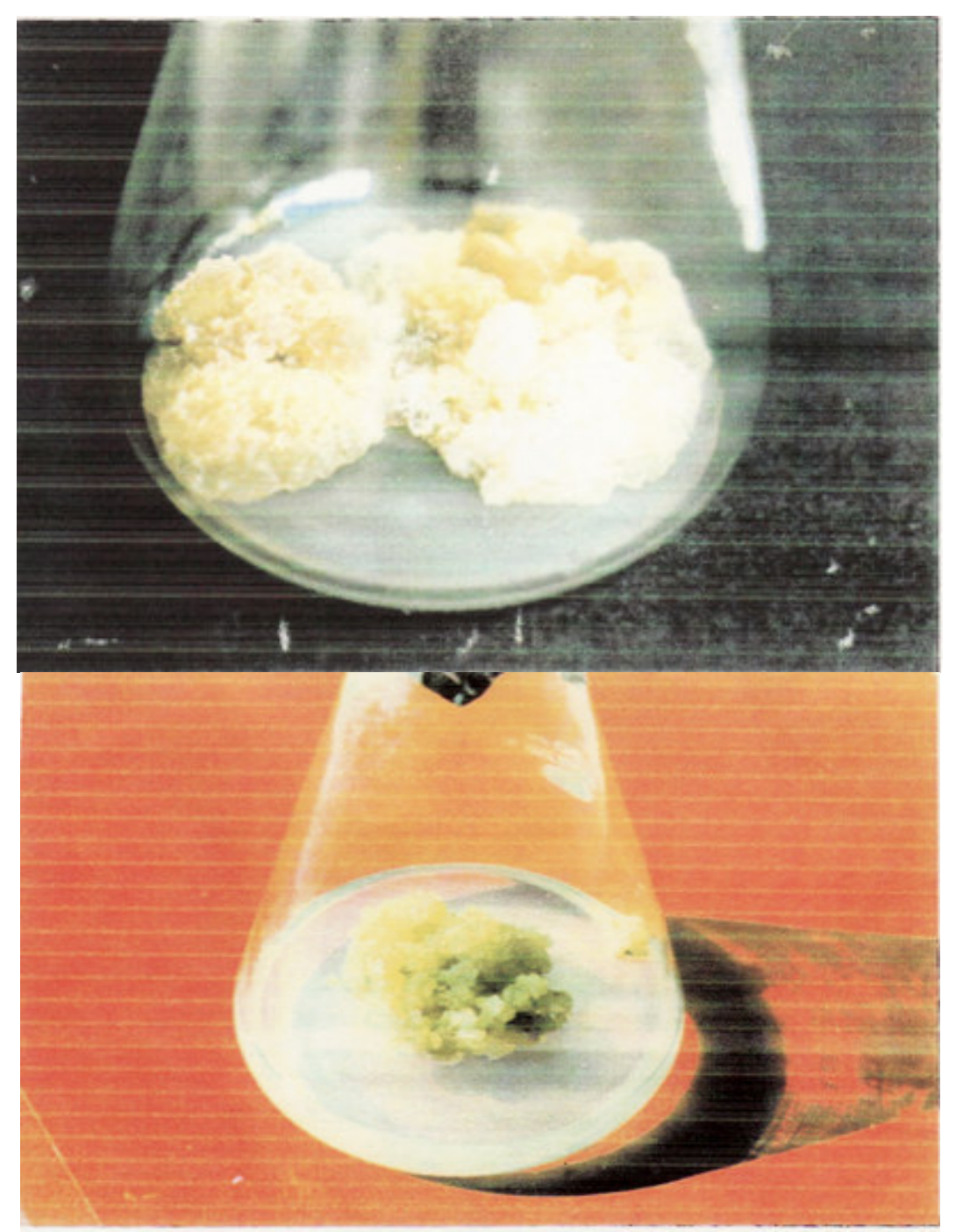

Fig.1- Regenerated callus in sugarcane Variety Co-740

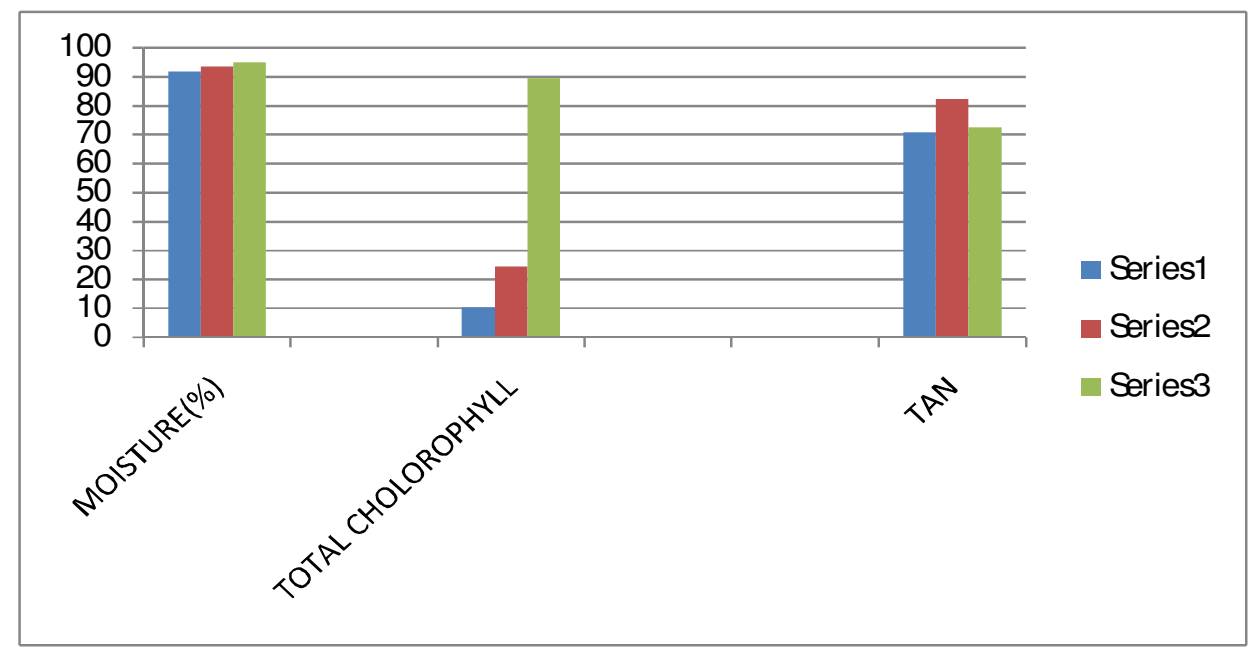

Fig. 2- Organic constituents in the different stages of regenerated shoots in sugarcane variety Co.740 (Series 1: IC, Series 2: IM and Series 3:- IR) 


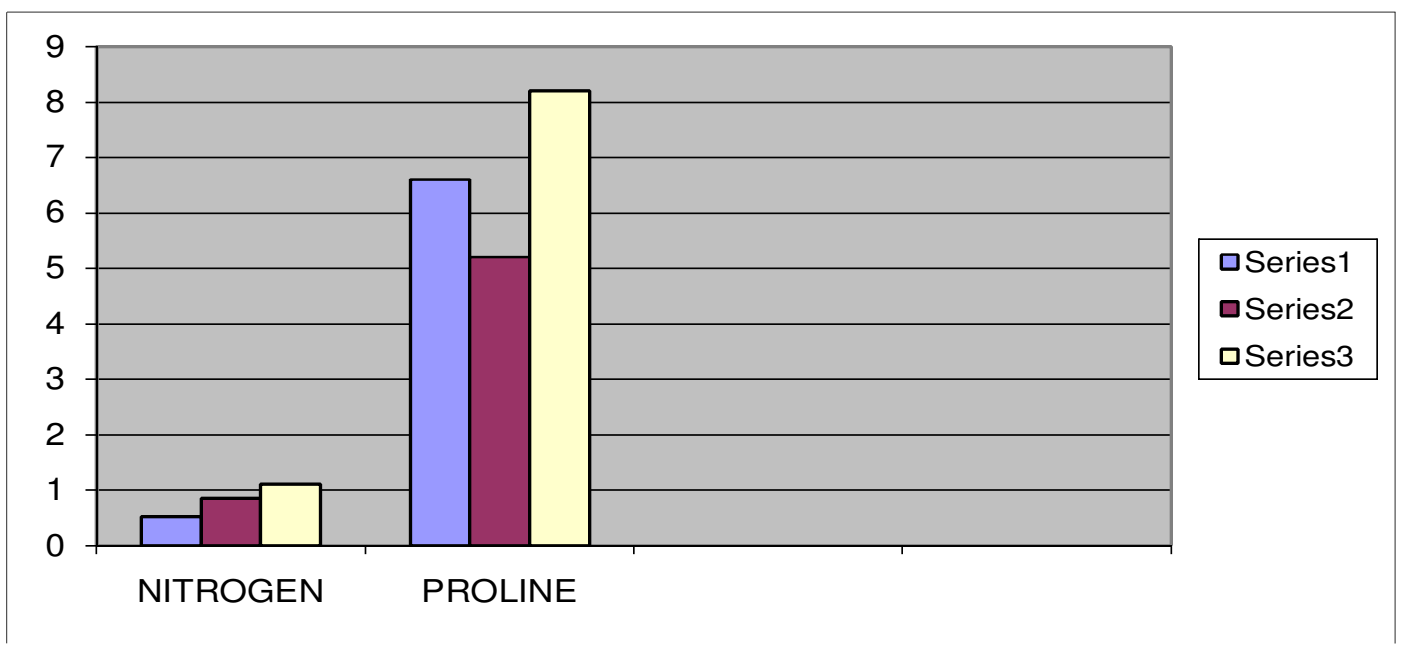

Fig. 3- Organic constituents (nitrogen and Proline) in the different stages of regenerated shoots in sugarcane variety Co.740 (Series 1: IC, Series 2: IM and Series 3:- IR)

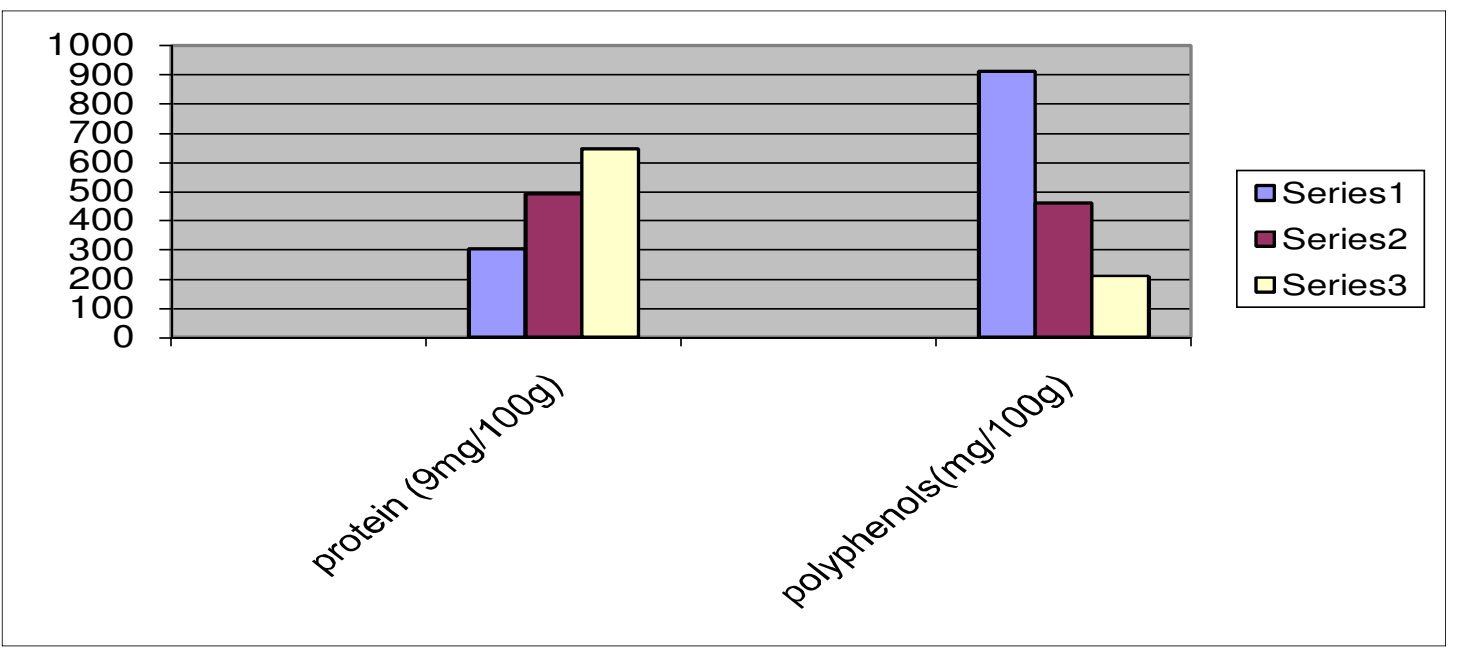

Fig. 4- Organic constituents (protein and polyphenols) in the different stages of regenerated shoots in sugarcane variety Co.7 (Series 1: IC, Series 2: IM and Series 3:- IR)

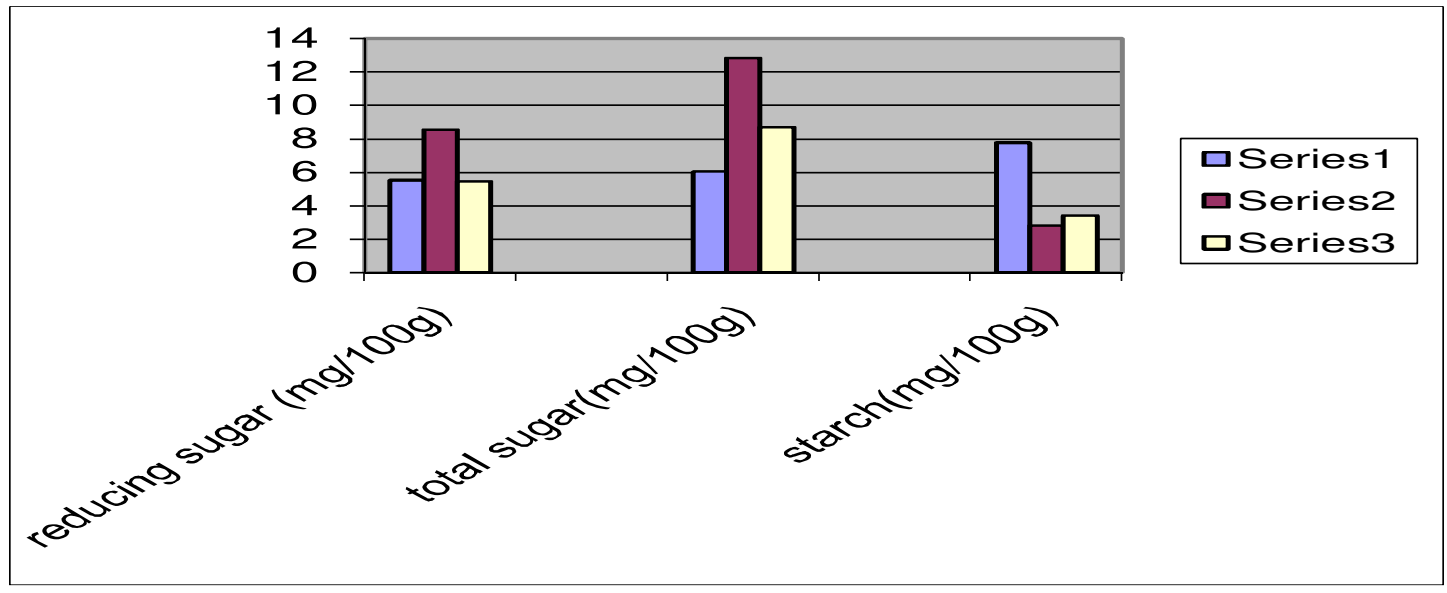

Fig. 5- Organic constituents (carbohydrates) in the different stages of regenerated shoots in sugarcane variety Co 740 (Series 1: IC, Series 2: IM and Series 3:- IR) 